\title{
Facilitated Telementoring for K-12 Students and Teachers
}

Judi Harris

College of William and Mary

Follow this and additional works at: https://scholarworks.wm.edu/educationbookchapters

Part of the Education Commons

\section{Recommended Citation}

Harris, J. (2010). Facilitated telementoring for K-12 students and teachers. In Berg, G.A. (Ed.). Cases on online tutoring, mentoring and educational services: Practices and applications (pp. 1-11). Hershey, PA: IGI Global. 


\section{Facilitated Telementoring for K-12 Students and Teachers}

Judi Harris

Professor and Pavey Family Chair in Educational Technology

School of Education, College of William \& Mary

Williamsburg, Virginia

KEYWORDS telementoring, e-mentoring, K-12, curriculum, facilitation 


\section{EXECUTIVE SUMMARY}

The Electronic Emissary is a Web-based service and resource center that helps teachers and students with Internet access locate mentors who are experts in various disciplines, then plan and engage in curriculum-based learning.. In this way, the interaction that occurs among teachers and students face-to-face in the classroom is supplemented and extended by electronic mail, Web forum, chat, and audio/videoconferencing exchanges that occur among participating teachers, students, and volunteer mentors. These project-based online conversations typically range in length from 6 weeks to a full academic year, as students' needs and interests dictate.

The Electronic Emissary has been online since February 1993 and on the World Wide Web since December 1995. It serves students and teachers globally, but the majority of its participants to date have been in North America. Emissary-related research has focused upon the nature of telementoring interactions in which K-12 students are active inquirers, the motivations and perceptions of their volunteer subject matter mentors, why some teachers choose to persist in integrating telementoring into curricula despite considerable hindrances, effective telementoring facilitation techniques, and what teachers learn as they help their students to participate in curriculum-oriented telementoring projects.

Students exploring complex curriculum-based topics need to actively build deep and sophisticated understanding. One of the most effective ways to do this is by engaging in ongoing dialogue with knowledgeable others, as the students form, refine, and expand their knowledge. Classroom teachers typically serve as the subject matter experts with whom students interact in curriculum-based areas of inquiry. Yet when the issues being explored are multi-disciplinary, technically and conceptually sophisticated, or dependent upon current and highly specialized research and theory, additional expertise must be made directly available to students and teachers longitudinally, and on an as-needed basis. This is what telementoring offers to learners and educators today, and what the Electronic Emissary brings to students and teachers worldwide.

\section{BACKGROUND}

Telecommunication tools and resources are providing teachers with new ways to engage their students in learning experiences that reflect how knowledge is built and used in the world outside the school. Today, a teacher no longer needs to be the sole content matter expert in the classroom. It is possible, for example, for students to learn about global warming from researchers studying ecological phenomena in the Antarctic, or to discuss the historical implications of a recently discovered primary source document with an historiographer, using simple telecomputing tools such as electronic mail and Web-based discussion groups. Volunteer subject matter experts, such as the ecological biologists and historians referenced above, can work virtually with students over an extended period of time, developing and sustaining mentorprotégé relationships that contribute to the richness and relevance of curriculum-based learning in elementary, middle-level, and secondary classrooms.

E-mentoring. Such online mentoring, also called 'e-mentoring' and 'telementoring,' holds great potential for both learners and teachers. When it is implemented to benefit elementary, middle- 
school, or high school-aged students, it "is a caring, structured relationship [that] focuses on the needs of the mentored participants, adds value to the lives of those involved, [and] uses technology to connect people across time and/or distance." (National Mentoring Partnership, 2002, as cited in Harris, 2003, p. 53) E-mentoring for K-12 students typically involves sustained exchanges between mentors and protégés who use electronic mail, discussion forums, chat, texting, and/or audio/video-conferencing to communicate. It differs from using ask-an-expert Web sites (e.g., the services indexed by the Center for Innovation in Engineering and Science Education) to answer specific questions in that telementoring generally lasts longer and achieves greater depth than simple question-and-answer communication online. E-mentoring for precollege students can involve one or more mentors and protégés, and can be used as an integral part of school curricula or for an extracurricular exploration of career interests, hobbies, or personal issues.

\section{Setting the Stage}

E-mentoring support. Support for online mentoring for K-12 students takes several forms, distinguished primarily by when and about what mentors and their student protégés communicate. Some e-mentoring services -- such as Achievement Advocate and iMentor -support students' interactions with mentors without teachers' direct involvement. These one-toone mentoring services involve individual students interacting with one mentor each, often discussing topics that are not explored as deeply (or at all) in school. Others, such as the International Telementor Program and the Electronic Emissary, are designed to assist students' curriculum-based learning during the school day, typically requiring direct involvement by participating students' teachers. As such, they can support either individual students or groups in ongoing communication online with one or more mentors.

E-mentoring facilitation. The ways and degrees to which students' communications with their mentors are monitored and/or actively facilitated is another important aspect of online mentoring for K-12 students. The time- and labor-intensive nature of this feature of telementoring has caused many services to decide against providing personalized facilitation of e-mentoring exchanges. Several, such as icouldbe.org, use text filters to screen for inappropriate language or topics addressed. Others, such as Connecting to Success, require participating students' teachers or parents to monitor all messages exchanged with mentors. Given current concerns about minors' safety in online interactions, and school districts' increasingly stringent Acceptable Use Policies for Internet activity, this challenge looms large for both the scalability and security of online mentoring for K-12 students, and concomitantly, the considerable time and resource costs of providing high-quality, safe, yet efficient online mentoring for them.

Integrating e-mentoring. When telementoring is designed to function within a schoolbased curriculum (as opposed to an extracurricular activity), it can help to bring subject matter alive in ways not possible within many communities, increasing the depth, breadth, and/or authenticity of students' curriculum-based learning. Communicating regularly with content specialists with active interest, experience, and expertise in school subjects can intensify students' engagement and connection with content, due to the highly interactive and personalized nature of telementoring discussions. Integrating regular e-mentoring discussions into students' classroom activities, however, presents pedagogical challenges for teachers who are unfamiliar with planning and implementing networked communication as part of students' schoolwork. To use online mentoring effectively within classroom-based learning, therefore, requires professional support for teachers, provided by educators who are familiar with the logistical 
realities of planning, instruction, and school contexts, along with the unique requirements of teaching and learning online.

E-mentoring assistance. Taken together, the essential characteristics and challenges posed by high-quality telementoring for K-12 students suggest the need for personalized assistance with planning and implementing curriculum-based e-mentoring projects that are completed in schools. Until more teachers are familiar and comfortable with integrating telementoring into classroom-based learning activities, active facilitation will be necessary to stem participant attrition and ensure quality learning experiences for students. Given the resource-intensive nature of providing this type of support, combined with shrinking school budgets, high-quality, curriculum-based telementoring is primarily a volunteer-based and grantfunded effort at the present time.

\section{CASE DESCRIPTION}

One example of grant-funded, school curriculum-based online mentoring that provides the personalized facilitation and oversight necessary to ensure high-quality learning is the focus of this case. The Electronic Emissary, a university-based telementoring service and research effort, brings together volunteer content specialists with K-12 students and their teachers to communicate about school curriculum topics in which the specialists have expertise. The Emissary has been online since the fall of 1992, and on the Web since December 1995. It began in the College of Education at the University of Texas at Austin, then moved (with its director) to the School of Education at the College of William \& Mary in fall 2002.

To our knowledge, the Emissary is the longest-running online mentoring service for elementary, middle school, and high school students, and the only one that offers personalized project planning, facilitation, and mentor development. Emissary staff members are graduate students and instructors with both school teaching experience and expertise in facilitating online learning and teaching who facilitate the telementoring projects part-time. Emissary-supported projects address academics primarily, and are planned and implemented with the direct and ongoing involvement of students' teachers or parents.

Funding. To date, the service has supported approximately 900 telementoring projects, with the number of concurrently communicating groups -- ranging from just a few to 75 or more -- determined by the amount of funding currently available. All telementoring services are provided free of charge. The Electronic Emissary has been supported by grants from the Texas Center for Educational Technology, the J.C. Penney Corporation, the National Science Foundation, the South Central Regional Educational Technology Consortium, the U.S. Office of Naval Research, and the School of Education at the College of William \& Mary. Grant funds pay for project facilitators' and programmers' time and effort. The Emissary is directed by a university professor of educational technology - the author of this chapter -- whose project work helps to meet her employer's expectations for professional service to the larger educational community. Server space for and online access to the Emissary's Web site is provided similarly pro bono by the Department of Information Technology at the College of William \& Mary.

Mentors. The Emissary's mentor database has included up to approximately 200 mentors, changing in size over time according to the number of currently active and available subject specialist volunteers. Approximately half are scientists; many work for universities or governmental agencies, and a sizable proportion are information technology workers. Lawyers, doctors, businesspeople, artists, and teachers are also included in the database. Most have had prior experience working with elementary, middle school, or high school students, typically 
through scouting, $4 \mathrm{H}$, religious groups, school-community partnerships, or museum-based extracurricular educational programs.

These volunteer content specialists typically work with only one telementoring project at a time. Additional mentors are requested periodically by posting invitations to academic and professional electronic mail distribution lists, discussion groups, and/or organizational Web sites - though currently, most new mentors are referred to the project by existing volunteers. These postings include directions that the prospective mentors can follow if they would like to add an information form about themselves to the Emissary's searchable, Web-based database. The information requested of potential mentors is extensive, and is used by the project director to screen the volunteers carefully before determining whether their form can be added to the active part of the mentor database. Employers are contacted to verify potential participants' responses as necessary. A portion of the information provided - specifically, the mentor's name, institution, work description, general location, areas of expertise, availability for communication each week, and past experience working with K-12 students - is made searchable and accessible at the Emissary's web site. All other information (e.g., telephone numbers; email addresses; employment details) is accessible only by Emissary staff members.

Teachers. The volunteer specialists' information forms are searched and reviewed by classroom teachers who are considering incorporating online mentoring into some aspect of curriculum-based learning for one or more of their students. (Parents who are seeking individualized mentoring for their children outside of school can also avail themselves of this opportunity.) To request the services of a mentor selected from the database, teachers must complete a similarly detailed information form about themselves, their school, and their students' learning needs and preferences. They must also describe completely the learning activity/ies into which telementoring will be integrated. An optional interactive project planning tool is available for teachers' use on the Emissary's web site to assist with this important planning process.

\section{CURRENT CHALLENGES}

Teachers' Challenges. This last piece of information that teachers must provide has proven to be one of the most important and challenging to specify. Online communication lacks the full spectrum of visual and audible information that we depend upon, often unconsciously, in face-to-face exchange. Therefore, mentoring online requires somewhat different interaction strategies if it is to be used to create maximal educational benefit. For example, more frequent and more explicit purpose-setting, progress-reporting, and problem-solving communications are typically necessary on-line than in face-to-face interaction (Kimball \& Eunice, 1999). The challenge is compounded when teachers attempt to weave online mentoring meaningfully into classroom-based, face-to-face teaching and learning. True mentoring involves relationshipbuilding and communicating regularly for an extended period of time in a focused way. Limited access to Internetworked computers in schools, strict policies banning online interaction with outsiders during school, pressure to "cover content" quickly in ways that will be reflected in students' standardized test results, and lack of experience with successfully integrating use of online technologies into curriculum-based learning have discouraged some teachers from pursuing curriculum-based telementoring opportunities for their students.

Facilitators' Challenges. The gravity of these challenges - and the typically high attrition rate in organized online projects of all types - helped the Emissary's staff to recognize the need for customized and personalized facilitation of each e-mentoring project it supports, from initial inquiry, through project planning, mentor selection, relationship-building, students' and mentors' 
online communication, problem-finding and-solving, and project evaluation. Each telementoring project's parameters, patterns, and events are unique, because each is designed for a specific student or group of students in particular classroom, school, geographic, cultural, economic, and curriculum contexts. Each teacher's and mentor's expectations, assumptions, communication patterns and past experiences are also different. In these complex combinations of variable, local factors lay both the potential power and fragility of any online mentoring interaction. Though online tools can be designed to assist with the customization necessary for online mentoring projects to succeed (as the Electronic Emissary's Web-based tools do), our experience suggests that direct and personalized facilitation by a knowledgeable educator is necessary for most curriculum-based telementoring projects to inspire truly meaningful, worthwhile learning.

\section{Solutions}

Facilitators. What do the Emissary's online facilitators do? Logistically, they contact mentors whom teachers have selected from the database via email, asking the mentors whether they are available and interested in participating in the online project that the teacher has proposed on behalf of her students. If the mentors agree (as they usually do), the facilitators then request a dedicated email list or discussion forum from the Emissary's director for the teacher and mentor to use to become acquainted and to plan the specifics of the project that the teacher has proposed. The facilitator participates actively in this online discussion, introducing the teacher and mentor to each other, answering their questions and offering suggestions about how to structure the online mentoring project to students' best educational advantage.

Once project plans are finalized, the facilitator requests one or more lists or discussion fora from the director for the students and teacher to use to communicate with the mentor. The facilitator actively monitors this exchange, messaging participants privately with suggestions and encouragement, or sending gentle reminders if communication lags. The facilitator can also contact participants by telephone, if necessary. When the project is complete-typically in six ten weeks' time -- the facilitator works with the teacher, mentor, and any available students to create a project summary that is added to the searchable database of Emissary-sponsored projects that is available at the Emissary's Web site. These summaries are used for inspiration by teachers creating proposals for new telementoring projects. The facilitator also encourages all participants to complete project evaluation forms, the data from which are used by the Emissary's staff to prompt procedural, policy, or resource changes that will benefit future Emissary participants.

Two researchers who studied different aspects of the online mentoring that the Emissary supports summarized the facilitators' roles as moderator, mediator, and facilitator:

- The facilitator may serve as a moderator during initial contacts as the participants are establishing the framework for the project. As moderator, the facilitator models the language, discussion techniques, and netiquette protocols necessary for quality communication in the online environment. In addition, the facilitator models proper use of the technical framework within which participants operate in order to assure quality communication.

- The facilitator may serve as a mediator as the project progresses. Tasks such as tracking down resources and materials that enrich the learning experience or providing technological assistance that supports learning goals--such as setting up a real-time chat or videoconference among teachers/students and mentors--may become part of the facilitation process. 
- And, the facilitator facilitates or engages the teachers/students and mentors in collaborative learning processes by planning with the teacher, monitoring on-line interactions, and providing guiding comments as needed. (McGee \& Boyd, 1995, p. 645)

More information about this complex and fascinating facilitation process is available in Harris \& Figg (2000).

\section{Sample Telementoring Projects}

The diversity, customization, and students' active engagement in the curriculum-based learning that the Electronic Emissary supports are best communicated by examining the projects themselves. Brief summaries of several, selected to demonstrate the range of different topics, grade levels, and types of online interactions that the Emissary has facilitated, follow.

- High school students in Delaware who were studying Nathaniel Hawthorne's The Scarlet Letter communicated with the character Arthur Dimsdale, who was actually an American literature professor at the U.S. Naval Academy. During the following semester, the students communicated with the professor himself about Mark Twain's Huck Finn, culminating their exchange by creating a newspaper that they called The Mississippi Times, an idea first suggested by the expert. The teacher and the professor shared instructional ideas, resources, and perspectives about Mark Twain's works and views.

- Students in the "upper room" of a country school in a rural and mountainous region of northern California (11 students, ranging from 4th to 8th grade in the same classroom) learned about bones and skeletons by studying their own skeletal systems and the bones found in owl pellets in the woods near their school. Their teacher, along with a biological researcher at Michigan State University, guided the students' hypothesis formation and testing as they extracted the bones from the pellets, measured them, labeled them, then reconstructed the skeletons, and deduced what kinds of animals the bones supported.

- Jannah, a 10-year-old student in Connecticut, corresponded frequently with Dr. Eisner, a professor in Arizona. They continued their study of Arthurian legends that begun in the spring semester of 1995 for more than three years. Jannah, Dr. Eisner, their online facilitator, and the Emissary's director co-authored an article describing their online educational experiences that appeared in the May 1996 issue of the professional journal, Learning and Leading With Technology.

- An Advanced Placement Spanish Literature class in Ross, California communicated with Bob Fritz, a professor of Spanish at Ball State University. All communication was conducted in Spanish. Topics addressed included the nivolas of Miguel de Unamuno and how these works fit into the cultural and historical contexts of Spain.

- 19 fourth- and fifth-grade students in McAllen, Texas compared the experiences of their families on the Texas "La Frontera" to colonial life in the original 13 U.S. colonies, with the help of the director of a historic preservation center and museum in Fredericksburg, Virginia.

- Eight groups of four girls each, studying in an honors science program at a New England high school, communicated with a graduate student at the University of Minnesota about DNA \& infantile leukemia (the topic of the subject matter expert's thesis), cancer research \& therapy, and professional careers for women in science. The teams discussed both scientific and ethical issues online with the university-based genetics expert.

- A computer scientist at the State University of New York-Potsdam with interest and expertise in American history posed as a young Union soldier to help gifted and talented 
fifth-grade students in Omaha, Nebraska learn about the Civil War. He answered the students' questions in character. The students used what they learned from his responses to write a play about the Civil War, which was performed at their school.

- Fifth grade students in Council, Idaho who were studying animal behavior - specifically, rats negotiating mazes of different types -- received suggestions on how to improve their observation techniques from a primate ethologist working at the Wisconsin Regional Primate Research Center.

- Ninth grade students from San Angelo, Texas corresponded with an anthropologist from Los Angeles, California about civil rights, both as they could be explored with reference to the first Rodney King trial (that was taking place at the time of the exchange) and historically, by examining the struggle for African American rights during the late 1950's and early 1960's, with particular emphasis upon the contributions of Dr. Martin Luther King, Jr.

- Third grade students from San Antonio, Texas communicated with a naval officer and meteorologist stationed at Fort Biloxi, Mississippi about atmospheric physics and atmospheric dynamics, even though, as the subject matter expert indicated, they probably didn't realize that their questions concerned such complex topics.

- Sixth grade students in Houston, Texas, who were engaged in multi-disciplinary study of the Middle Ages, posed questions to a medieval history professor who worked at the University of Illinois, addressing her as "Learned Sage." She, in turn, answered their questions, calling them "Seekers of Knowledge."

- Fifth grade students in Amarillo, Texas communicated with a researcher from A, T \& T Bell Laboratories about sailing and celestial navigation. The subject matter expert in this team both answered questions and suggested simple experiments for the students to try to help them to understand the information that he was communicating.

- Eleventh and twelfth grade students in La Crosse, Wisconsin who were working on labs about the scintillation of light, extinction of light, and variable stars, consulted a nearby university-based physicist, who, we soon learned, had known their teacher before the Emissary project "matched" the team.

- 16-to-18-year-old students from Salmon Arm, British Columbia, who were curious about virtual reality technologies, corresponded with a computer scientist working for Boeing and NASA, later commenting upon his skill in using humor and professional anecdotes to help them to understand technical information.

- Fourteen gifted high school students from Nacodoches, Texas interacted online with 14 different subject matter experts on topics of individual and mutual interest and research, including: marine biology, blues music, harmony in music, computer graphics, the Elizabethan era, biomechanics, black holes, documentary direction and production, the physics of fire-fighting, the effect of the media on public opinion, genetic engineering, the New Age movement, reincarnation, and the effect of day care on child development.

Benefits. Members of Emissary-supported e-mentoring teams are engaged in in-depth, dynamic exchange. Project evaluation results provided by team members have emphasized the importance of the relationships that have developed among participants. Subject matter 'came alive' for students who could interact with someone for whom curriculum content is part of everyday life and a passionate interest. Many participating teachers develop close, apprentice-like relationships with the mentors, requesting and receiving assistance with content-related concepts, resources and activity design. Mentors often delight in opportunities to revisit and delve deeper into their 
disciplinary specializations by interacting with interested but less knowledgeable others. Facilitators express fascination with the often challenging, personal and in-depth communication co-created by people who know each other only virtually.

\section{IMPACT}

Why pursue e-mentoring that is integrated into curriculum-based instruction in schools, especially noting the considerable challenges that it presents? Participating students, mentors, and teachers have shared stories of how deeply and positively these interactions have impacted them - far beyond what even the Emissary's staff had hoped. Several examples follow here.

After serving as a mentor several times, a managing editor for an online magazine decided that teaching was her "true calling:"

The experience that I had in helping a group of high school students translate their school newspaper to the Internet inspired me to return to school and become a certified teacher. I will hopefully begin teaching, in New York City, this fall. I am putting together my resume and want to include the experience that I had with Electronic Emissary. ... This experience was really essential to my decision to teach. The marrying of all the things I love -- technology, kids and the written word -- was so complete in this one project that it taught me what I could someday do in my own classroom. Thank you for the opportunity to learn this valuable lesson.

She continues to be listed in the Emissary's database, now describing her work as a "teacher of literacy for $8^{\text {th }}$ grade."

A teacher in an impoverished urban school sent the following message to her class' mentor, a software designer at a large technology corporation:

It was fascinating to see the kids react to your last suggestions. They came in on Saturday morning so they could work for a couple of hours straight. When you mentioned not understanding question 8, Neil replied that he didn't understand it either, and he was the one who wrote it. Your answers were awesome, yet some of them made the kids uncomfortable. I've come to believe that this is one of the best things you could do for them and I need to do more of it.

Let me see if I can explain. Our school has a high poverty rate - approximately $70 \%$ of the students receive free or reduced lunch and an equal number are minorities. In fact, all of the students you are e-mailing qualify as minorities in some capacity. Teachers here work so hard to encourage students to perform that maybe we don't set high enough expectations for our brighter kids. This group of students thought that because they'd come up with an idea, it was good. You challenged them to expand their thinking. They realized that in some cases they needed to abandon ideas and start over. The time they spent getting to those ideas wasn't spent in vain, but they haven't realized this yet. They pored over all of your messages again and were deep in thought for quite awhile. The kids had to submit their project ... on Saturday, but they are on the verge of their best thinking, so I want to encourage them to spend a little more time developing their product.

You should hear from the kids before the end of the week, but I just wanted to give you a glimpse behind the scenes. Even after your brief encounters with them, they trust what you tell them. They recognize your expertise and they really do think about and 
discuss what you tell them. It's really neat to see them grasp what you mean over time. I've left the messages in a folder and they take turns reading them aloud and then rereading them. I'll be presenting ideas about integrating technology to preservice teachers at a local university next month and will definitely mention the Electronic Emissary Project. You are the best thing that's happened to us all year and I can never thank you enough.

The power and inspiration experienced by all of the participants in this science project, even after only a short time communicating with each other, attests to why it is important to continue to work with teachers, mentors, and students to offer online mentoring as part of curriculum-based work in school, despite the challenges inherent in doing so.

In conclusion, please consider the following Electronic Emissary experience, summarized by a past high school student participant with severe cerebral palsy who worked for several years online with a retired journalist with multiple sclerosis. The statement is shared here with her permission.

I remember the day I applied for a mentor in the Electronic Emissary program. Midway through my sophomore year in high school, I was summoned from my English class by my academic advisor and another teacher who had connected with me as a fellow bookworm. They knew that, as an accelerated student, I had already surpassed the expectations of the classroom teacher and consequently, that my proficiency and skills were not developing. I was looking for an enriched experience, and they thought they had located one.

On the school's sole public computer with Internet access, located in the library, they brought up the EE website. For the first time, I was presented with options of what I wanted to study and with which professional I wanted to work. Scanning the list of mentors was like pouring through a college bulletin of course offerings. Even though I was still in high school, where, in the realm of English classes, one size fit all, I could have access to and develop a relationship with any of these dedicated professionals. After serious consideration of my long-term academic and vocational goals, I chose to work with a retired journalist who offered to train me in writing book reviews. This sounded perfect: I would have a mentor to discuss a variety of books with me in depth on a weekly basis, expanding beyond the three-books-a-year curriculum at high school. I imagined that the experience would introduce me to the field of journalism and publishing, helping to solidify my ambitions.

The relationship blossomed as we corresponded at great length over the weeks. My mentor and I soon discovered that we shared a few things in common in addition to our love of literature. Although we never met in person, we lived not far from each other, both in rural settings raising animals. What's more, we both live with severe physical disabilities. For the first time, I had interaction with a role model who had achieved success in my intended field of work. Her accomplishment was a profound inspiration to me, confirming that I could pursue my dreams, despite my physical challenges. Providentially, the nature of the EE program eliminated the obstacles to verbal communication that I face in a crowded classroom. Using e-mail, I could express my 
questions and observations without time constraints and I was always understood. I received more support and attention on-line than a classroom teacher could offer.

Although the formal EE mentorship was intended to last the duration of one semester, my mentor and I continued to work together more or less independently for the remainder of my high school years. I made measurable progress in my writing skills and consistently benefited from her extensive feedback; we agreed that it was valuable to maintain the relationship beyond the EE framework. I grew as a writer because my mentor encouraged me to revise each piece based on her suggestions, holding me accountable for my writing. No other instructor at that time demanded that I internalize increasingly mature conventions of grammar and style. My mentor guided me in developing a professional voice: she asked me to identify and consider the needs of the public audience who would be reading my book reviews. She helped me to think critically - reflectively, not reflexively. With her support, I mastered the form of the book review, modeling examples in The New York Times. Even before attending college, I had gained ample experience and skills in my intended profession.

Since participating in the EE program, I have graduated from a prestigious university with a degree in English literature. I followed through with the goals that I first identified when enrolling in the EE program. Now I have embarked on a career in editing and publishing, working for a journal. Ironically, my job description also entails developing and managing an on-line mentor program with physically challenged young adults to develop their writing skills.

Perhaps more than any other, this story serves as a living example of the tremendously transformative power of connecting motivated, caring individuals with similar interests over time and across geographic distance in personalized ways. The impressive benefits of online mentoring for K-12 students have been clear and demonstrable enough during the Electronic Emissary's many years linking students, teachers, and volunteer content specialists to warrant addressing and overcoming the challenges inherent in doing so. 


\section{REFERENCES}

Center for Innovation in Engineering and Science Education. (2009). Ask an expert sites. Retrieved January 26, 2009 from http://www.ciese.org/askanexpert.html

Colorado Nonprofit Development Center (2007). International Telementor Program. Retrieved January 26, 2009 from http://www.telementor.org/

Harris, J. (2003). Seek strategically, find answers appropriately. Learning \& Leading with Technology, 30(6), 50-53.

Harris, J.B. \& Figg, C. (2000). Participating from the sidelines, online: Facilitating telementoring projects. ACM Journal of Computer Documentation, 24(4), 227-236. Available: http://portal.acm.org/citation.cfm?id=353927.353934

icouldbe.org inc. (n.d.) icouldbe.org: Mentoring the next generation. Retrieved January 26, 2009 from http://www.icouldbe.org/

iMentor, Inc. (2009). iMentor. Retrieved February 19, 2009 from http://www.imentor.org/

Kimball, L., \& Eunice, A. (1999, November). Zen and the art of facilitating virtual learning communities. Paper presented at the ThinkQuest Teachers' Summit, Los Angeles, CA.

McGee, P. A., \& Boyd, V. (1995, March). Computer-mediated communication: Facilitating dialogues. Paper presented at the annual meeting of the Society for Information Technology and Teacher Education, San Antonio, TX.

School of Education, College of William \& Mary (n.d.) Electronic Emissary. Retrieved January 26, 2009 from http://emissary.wm.edu/

Student Achievement and Advocacy Services (2009). Achievement Advocate online mentoring community. Retrieved January 26, 2009 from http://www.achievementadvocate.org/default.asp

The Regents of the University of Minnesota (2007). Connecting to success: Mentoring through technology to promote student achievement. Retrieved February 19, 2009 from http://ici.umn.edu/ementoring/default.html 


\section{SUPPORT MATERIALS}

Questions and Answers

\section{How can telementoring support K-12 students' learning?}

Online mentoring can support both in-school, curriculum-based learning, and outside-ofschool, avocational learning and career exploration. When coordinated by teachers, ementoring projects for individual students or groups can be integrated into curriculumbased schoolwork. When supported by parents or guardians, telementoring exchanges can help students to explore extracurricular interests and career plans.

2. What are the primary advantages of incorporating telementoring into students' learning? State-mandated school curricula are often fact-heavy and disjointed. Twenty-first century learning emphasizes information-based problem-solving, critical thinking, multidisciplinary connections, and tolerance for the ambiguity and complexity of the postmodern world. Personalized communication with mentors whose work addresses school curriculum topics directly can help to make school-based learning more relevant for students.

3. What are the primary challenges to incorporating telementoring into students' learning? Telementoring that is well-integrated into students' curriculum-based learning requires personalized assistance that can be automated only minimally. The costs of providing such individualized professional development and support are not currently included in schools' operating budgets. Currently, directly facilitated telementoring services are provided only as volunteer efforts with minimal grant funding.

4. How extensively is telementoring used with $\mathrm{K}-12$ students at present?

A minority of teachers incorporate telementoring into curriculum-based instruction because of the time-related preparation and implementation challenges in doing so. With increasing pressure to "cover content" as measured with standardized tests, the in-depth and personalized learning yielded from telementoring is not often seen as a priority in classroom-based instruction.

5. What are the future plans for the Electronic Emissary?

The Emissary is structured purposely so that it can provide e-mentoring services to varying numbers of K-12 students and teachers over time, based upon available funding and support personnel. Since teacher demand is modest at present, and mentoring and project direction are provided by volunteers, the Emissary will probably continue to operate on a small scale in the short term. We are hopeful, however, that over time, increasing numbers of teachers will choose to incorporate e-mentoring into curriculum-based learning and teaching.

\section{BIOGRAPHY}

Judi Harris is a professor and the Pavey Family Chair in Educational Technology in the School of Education at the College of William \& Mary in Virginia, where she coordinates the Curriculum and Educational Technology doctoral program.

Dr. Harris' research and service focus upon K-12 curriculum-based technology integration and teacher professional development. During the past 28 years of her work in educational computing, she has authored Way of the Ferret: Finding and Using Educational Resources on 
the Internet (1994 \& 1995, ISTE), one of the first books about K-12 educational use of the Internet; Virtual Architecture: Designing and Directing Curriculum-Based Telecomputing (1998 \& 2009, ISTE); Design Tools for the Internet-Supported Classroom (1998, ASCD); and more than 200 other research and pedagogical publications on curriculum-based applications of educational technologies.

Prior to moving to William \& Mary in 2002, Dr. Harris served on the faculty of the University of Texas at Austin for ten years, where she founded and directed WINGS Online ("Welcoming Interns and Novices with Guidance and Support Online"), a suite of online mentoring services that support new teachers in multiple ways. That work became the foundation of William \& Mary's ENDAPT ("Electronic Networking to Develop Accomplished Professional Teachers;" http://endapt.wm.edu/), a second-generation suite of online services for new teachers. Her nonprofit Electronic Emissary (http://emissary.wm.edu/) telementoring service and research effort, begun in 1992, is the longest-running K-12 effort of its kind, and has served students and teachers worldwide. 